\title{
Editorial
}

\section{ISLANDS AN APPROACH TO UNDERSTANDING THE WORLD}

\author{
Jean Ross
}

This edition of Contemporary Research Topics Scope: Health \& Wellbeing 6, engages with the theme, islands. In this publication, an opportunity arises for authors to reflect, discuss and debate how islands may be considered and understood in relation to health and wellbeing. This sixth edition offers a space in which to recognise differing disciples' perspectives, theoretical underpinnings, and engagement with islands in which to bring a deeper understanding of the varied relationships and connections we have with islands. Islands are considered as being surrounded by water; land carrying capacity; positioned within a certain time and space; connected/disconnected; isolated; habituated; having similarities/differences/challenges; a place to relax; to travel to/from or community. There are many ways to consider islands, photographer Kevin Miles's interpretation on the cover of this Journal has the potential to provoke interest in this camera-less photographic image in which reader's traditional concepts may be transformed by the photographer.

The overall exploration in this Journal is to open local, national and international debate to enhance dialogue related to health and wellbeing and the concept of islands. Figure I below, depicts what islands means to me, my identity and sense of place and belonging, and relates to the ocean, space, isolation, connected, functional, a habited island of a working lighthouse keeper and family; however over time this island has been transformed by technology and the lighthouse has become non-manned. However this island is still habited by visitors and wildlife. South Stack, situated on the Irish coast between Holyhead, North Wales, and Dublin, Ireland and is a place my family would visit and walk down and up the 365 steps to the lighthouse on Sunday afternoons (the family walk following Sunday lunch which was always a traditional roast).

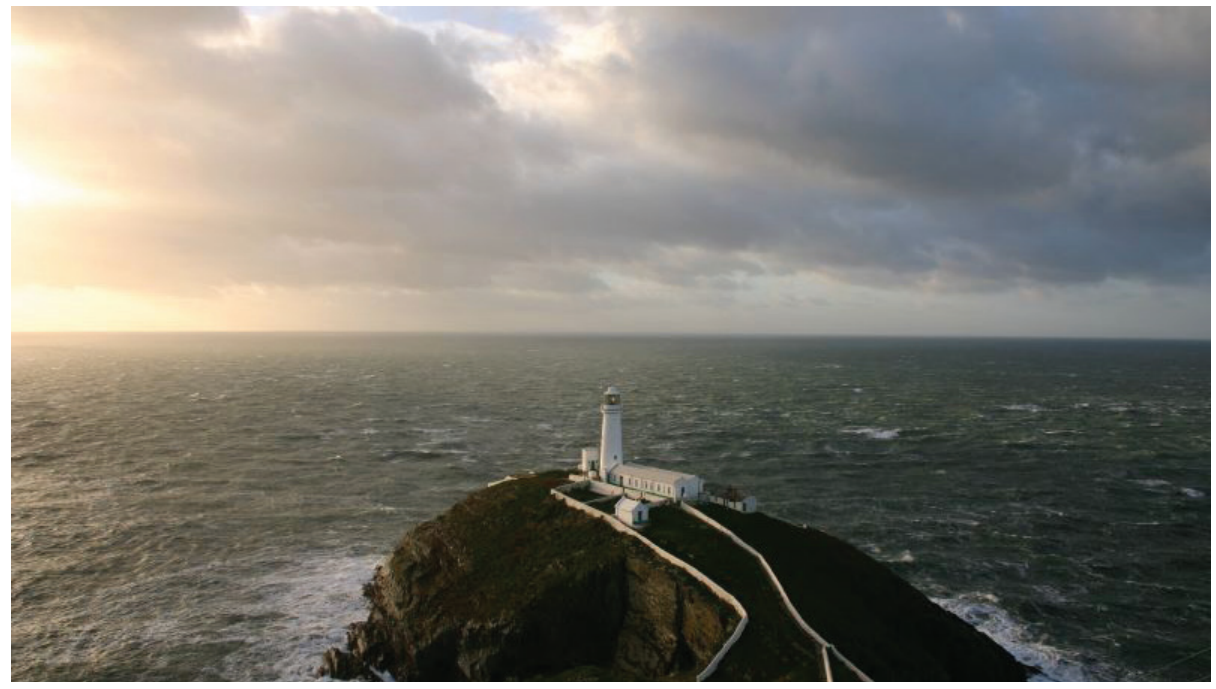

Figure I. South Stack lighthouse by "Deiz92", sourced from Flickr. Used under Creative Commons Attribution Non-Commercial No-Derivatives licence, CC BY NC ND 2.0. 
The outline of the Journal engages, expands and integrates, the concepts of islands as physical, tangible and visible, imagined, meaningful and reflective which are considered widely by the contributors in this Journal. Josie Crawley's original poem, a reflective contribution titled 'Diagnosed an Islander', projects her connection with islands which is further depicted with her photographic image of Kapiti Coast driftwood situated in New Zealand. A further two personal reflective contributions include an interview by Keith Whiddon with Hope Robson, a young vibrant women connected to the rural community of Bishop's Castle, Shropshire, UK, who is a social prescriber within this community and is also working towards establishing a community hub. A further reflective piece by Roberts considers islands and community life which further connects with this editorial as both our reflections are situated from the same costal location our upbringing surrounded and dictated by this coast including the image of Holyhead harbour. Robert's reflection also considers the influence of the COVID-19 pandemic on island life. This reflection is nicely positioned to proceed Cherrington, Dunn and Airehrour's commentary which also focuses on the pandemic as they express cracking the COVID-19 code. Cooper, Dhamja, Youard and Macgregor 's research interprets public gyms as 'islands' of community members, although their research was conducted prior to the COVID-19 pandemic, the findings are a significant reminder of the increased spread of respiratory disease that can transpire within the 'island' concept of gyms.

The remainder of the Journal presents four comparable papers comprising a wide range of new approaches that could improve health outcomes. All four papers enhance our awareness and considerations of health disparities, health inequities, with considerable emphasis of vulnerable population or cultural groups as islands of people who reside in Aotearoa. In this section, Sehgal and Cherrington's commentary stresses the importance of engaging with artificial intelligence to assist in reducing health inequities to improve health outcomes. In the following paper, Moore argues that seclusion, as a treatment to improve mental health outcomes for Māori is not affective, instead providing a cultural safe environment which embodies a therapeutic relationship is promoted. The third paper in this section supports Austin's literature review and discusses the stigma surrounding obesity and the role healthcare practitioners have in improving health outcomes of clients. The focus on improving health outcomes with vulnerable populations continues in the fourth paper, highlighting specific barriers experienced by Filipino migrants with the New Zealand healthcare system demonstrating the need for culturally safe integrated and enhanced migrant services that are specific to Filipino people.

I invite you to engage with the authors' contributions and progress in ongoing dialogue. I am open to letters to the Editor in future Journals.

Jean Ross (10 https://orcid.org/0000-0003-2467-92330000-0003-2467-9233 is Associate Professor and has been working at Otago Polytechnic Ltd | Te Kura Matatini ki Otago since 2003. She is a Registered Nurse, holds a BN and a Master of Arts, and completed her Doctorate in 2017. She was made an Associate Professor in 2018. From 1994-2003, she was co-director of the National Centre for Rural Health and instrumental in the development of interdisciplinary postgraduate nursing education. In 2008, she received the Rural General Practice Network Peter Snow Memorial Award in recognition of her national contribution to rural health research.

Correspondence to: Jean Ross, Otago Polytechnic | Te Kura Matatini ki Otago.

Email: jean.ross@op.ac.nz 